\title{
A survey on power management strategies of hybrid energy systems in microgrid
}

\author{
G. R. Prudhvi Kumar, D. Sattianadan, K. Vijayakumar \\ SRM Institute of Science and Technology, Kattankulathur, India
}

\begin{tabular}{l}
\hline \hline Article Info \\
\hline Article history: \\
Received Apr 22, 2019 \\
Revised Oct 23, 2019 \\
Accepted Nov 3, 2019 \\
\hline
\end{tabular}

\section{Keywords:}

Distributed generation

Microgrid

Power management

\begin{abstract}
The power generation through renewable energy resources is increasing vastly, Solar energy and Wind Energy are the most abundantly available renewable energy resources. The growth of small scale distributed grid networks increasing rapidly in the modern power systems and Distributed Generation (DG) plays a predominant role. Microgrid is one among the emerging techniques in power systems. Power Management is mainly required to have control over the real and reactive power of individual DG and for smooth operation, maintaining stability and reliability. This paper presents a survey of the research works already reported focusing on power management of hybrid energy systems such as mainly solar and wind systems in microgrid. Six different approaches have been studied in detail for AC, DC and hybrid AC/DC microgrid.
\end{abstract}

Copyright $\odot 2020$ Institute of Advanced Engineering and Science. All rights reserved.

Corresponding Author:

G. R. Prudhvi Kumar,

SRM Institute of Science and Technology,

Kattankulathur, India.

Email: eeecd.pruddu@gmail.com

\section{INTRODUCTION}

The advancements in electric industry such as deregulation and distributed generation (DG) have improved significantly to resolve the energy and environmental problems. With the rapid development of DGs and power electronic technologies, the concept of microgrid came into existence [1-4]. The different scenarios in microgrid will be AC type, DC type and Hybrid AC/DC type formed because of structural and functional differences. Microgrid generally termed as a localized group of electricity sources and loads. Connected Mode and Islanded mode are the two modes of operation for microgrid, connecting to the utility grid and absorb/deliver power from/to the power system in case of connected mode and microgrid works autonomously by isolating from the utility grid.

The interest grabbing towards the combination of renewable energy sources to power system as microgrids is able to obtain high reliability and flexibility [5, 6]. The drawback of hybrid microgrid is not able to handle various types of loads as rated ac frequency for ac grid and rated dc voltage for dc grid. The combination is the hybrid microgrid, which faces difficulty in the operation. Considering different rated ac frequencies and dc voltages, a new methodology proposed in [7]. Figure 1 shows the topology of the microgrid consists of AC and DC BUS with Solar and Wind Turbine as generation sources and connected to Utility grid by bidirectional ac/dc converters (BADC) and bidirectional dc/dc converters (BDDC). The different issues such as voltage sag, harmonics, voltage flickering occur in the autonomous mode operation of microgrid, the issues were handled in [8-11].

Enabling smooth and proper working of microgrid is very crucial and power management plays a prominent role. The power management strategy mainly helps to regulate the technical aspect like voltage and frequency of the microgrid, proper sharing of power between load and distributed generation [12-15]. It's very challenging to provide reliable and efficient power supply to the remote areas where sustainable power infrastructure is difficult to set up [16] to operate the microgrid quickly even with multiple DG units. 
The real and reactive power requirement of load will be shared based on the reference of DG units [17]. The review work mainly focuses on Power Management by considering various DGs for best performance of microgrid. This paper mainly brief on power management in DC microgrid, hybrid microgrid. The role of energy storage devices, utilization of hybrid energy storage, techniques based on multi agents and multi objective optimization.

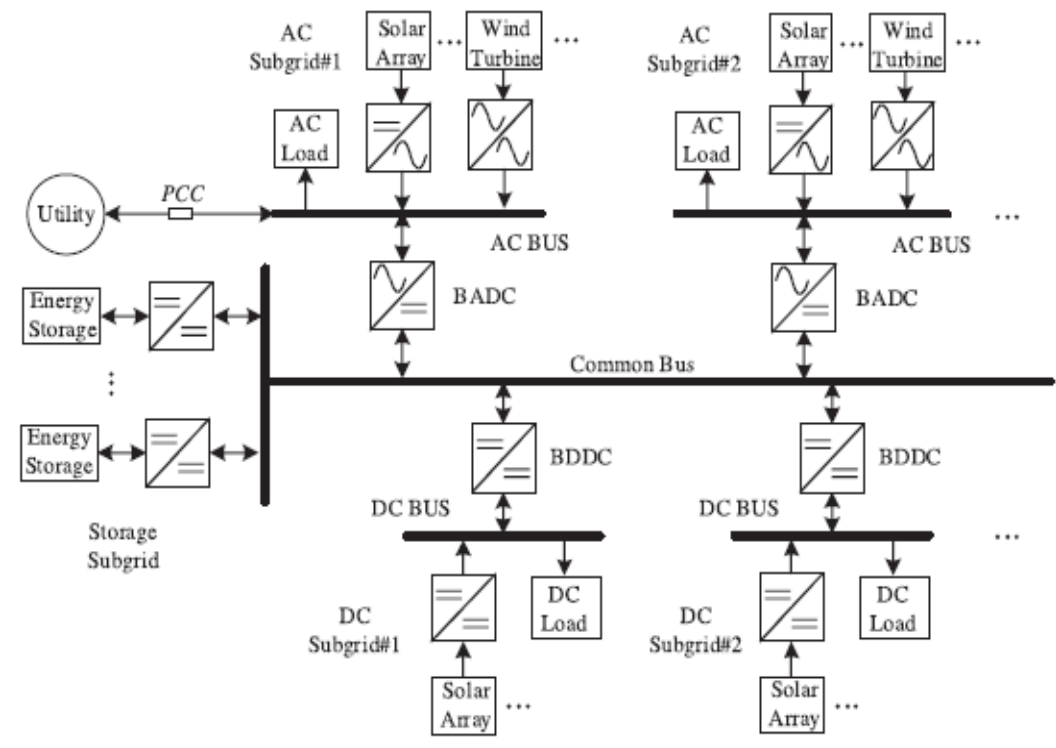

Figure 1. Topology of microgrid

\section{POWER MANAGEMENT STRATEGIES}

The Placement of Distributed Generations plays prominent role in management of power, it involves the need for best DGs. DGs based on the rating, location and the technique adopted for the interconnection to the system depicts proper power management. The principal and primary task in power management is to collect information regarding microgrid such as initial cost, power generated and load demand. The real and reactive power exchange between microgrid and the main grid will be determined and stabilizes the microgrid during the transition from grid-tied mode to autonomous mode. Main Features of power management include controlled power quality, controlling storages, considering load types and subgrid capacity, accommodating multiple subgrids. Based on power balance, Normalized voltage and frequency also management of power will be done. Based on duration, classified as long term and short term power management. Preplanning of generation and meeting load demand comes under long term management, regulation of rms voltage, control of frequency and instantaneous power requirement.

\section{POWER MANAGEMENT IN HYBRID AC/DC MICROGRID}

The authors in [18-22] given basic overview of power management in hybrid microgrid concentrating on the role of droop control and power flow control. Poh Chiang Loh [23] investigated power sharing issues in an autonomous hybrid microgrid, the management of power flow is tougher in hybrid microgrid than the earlier efforts developed for only AC or DC microgrid, This paper initially discussed about existing droop control for both AC and DC subgrids and then explained the coordination of both subgrids using interlinking converters. The Interlinking of two subgrids is mainly done to handle the case when any failure of subgrid occurs due to over stress, keeping individual source variations as small, reducing back-up reserve as one is sufficient to handle for both the subgrids. Highlighted some of the difficulties in interlinking two subgrids such as managing bidirectional power flow between subgrids, proper merging of two different droop equations of subgrids is highly needed. Proposes a normalization process with the appropriate droop control scheme. Navid Eghtedarpour [24] considers the management issues in ac and DC microgrids and proposes a decentralized power sharing method which will be flexible in locating the sources. Interlinking converter handles bidirectional power flow and power sharing between energy sources. Modified droop control strategy is proposed to address the issues in communication link. 
Considering two different scenarios such as dc microgrid near to overload and excess power in ac microgrid, ac microgrid near to overload and excess power in dc microgrid. Illustrated the proposed droop control for interlinking converter on power sharing in microgrid. P.C Loh [25] also come up with the idea of using an interlinking converter for power management in hybrid microgrid compared to his earlier works in [23]. The combination of general methodology of droop control with the DC link converter and energy storage proposes a control scheme for interlinking converter, the autonomous control for interlinking converter is responsible to link the AC and DC subgrids. The placement of sources does not affect the power sharing but source ratings will influence much. The proposed control method was tested using an experimental setup and also demonstrated the proper charging and discharging of energy storage. Peng Wang [26], proposes a hybrid three port ac/dc/distributed storage microgrid. A two stage interlinking converter is connected between AC and DC buses, the intermediate dc link will be treated as distributed storages. A fully decentralized control utilizing droop control method for power sharing in AC network and DC network processed locally, normalizing and combining the two different droop characteristics globally for proper control and power tuning on two stage interlinking converter. A multilevel power exchange is proposed with the different combinations of local, global and storage power sharing to reduce storage loss and increasing the lifetime of storage devices. With the help of a prototype the proposed control scheme is simulated and presented simulation results. Yanghong Xia [27] proposes a simple control strategy for power management of multiple subgrids, operating with multiple rated ac frequencies and dc voltages. The common bus from multiple subgrids was connected with bidirectional ac/dc and bidirectional dc/dc converters. Steady state and dynamic relationship in the proposed droop strategy is linear which improves the performance storage of subgrid. The common DC link voltage is maintained by forming storage subgrid, which eases to manage. Based on power shortage or surplus in the subgrids, the ac frequencies or dc voltage will become either lower or higher, thus droop strategy controls subgrids. The proposed method is validated in RTLAB by considering islanded mode containing multiple ac, dc subgrids and storage subgrid. As shown in Table 1 illustrates the research work carried in power management methods considering different strategies and features.

Table 1. Different strategies and features of power management methods in hybrid microgrid

\begin{tabular}{|c|c|c|c|c|c|c|}
\hline \multirow[b]{2}{*}{$\begin{array}{l}\text { Power } \\
\text { Management } \\
\text { Methods }\end{array}$} & \multicolumn{2}{|c|}{ Main Strategies } & \multicolumn{4}{|c|}{ Main Features } \\
\hline & $\begin{array}{l}\text { Based on Normalized } \\
\text { Voltage and } \\
\text { Frequency }\end{array}$ & $\begin{array}{c}\text { Based on } \\
\text { Power } \\
\text { Balance }\end{array}$ & $\begin{array}{c}\text { Power Quality } \\
\text { Control }\end{array}$ & $\begin{array}{c}\text { SOC Control } \\
\text { of Storages }\end{array}$ & $\begin{array}{c}\text { Consider } \\
\text { Load Types and } \\
\text { Subgrid Capacity }\end{array}$ & $\begin{array}{l}\text { Accommodate } \\
\text { Multiple } \\
\text { Subgrids }\end{array}$ \\
\hline Ref. [23] & Yes & & Yes & & & \\
\hline Ref. [24] & & Yes & Yes & & & \\
\hline Ref. [25] & Yes & & Yes & Yes & & \\
\hline Ref. [26] & Yes & & Yes & Yes & & \\
\hline Ref. [27] & Yes & & Yes & & Yes & Yes \\
\hline
\end{tabular}

\section{POWER MANAGEMENT IN DC MICROGRID}

References [28-30] dealt the power management concept for DC microgrids. Grzegorz Iwanski [28] proposes using super capacitor as an energy storage device, focused on the objectives such as over voltage protection, maintaining voltage balance in DC bus and the super capacitor overcharge and discharge protection. A variable speed power generation system with a power electronics converter between permanent magnet generator and DC link, additional converter between DC link and energy storage considered for Power management method. Four PI voltage controllers were involved in which two for DC bus voltage controlling and other two for protection, these will produce reference current of energy storage. DC link voltage will be greater than the voltage of the super capacitor during energy surplus mode, the energy will be transferred to storage and reverse direction in the case of energy deficit. Depending on reference current i_sc the charging and discharging of SC works, maximum power withdraws from SC during power shortage and reference current i_sc reaches positive maximum. Overcharge or discharge will be prevented by keeping reference current near to zero.

Luis E.Zubieta [29],Mengchu Zhao [30] also worked on the power management concept for DC microgrids. Luis E. Zubieta [29], presents a mean communication between the microgrid components uses DC bus voltage. Independent of the mode of operation in microgrid, the energy storage system always controls the DC bus voltage. based on power and energy management rules, the values will be set to receive responses from the other components. The proposed concept reduces grid disturbances and energy management conditions, Optimization of the use of resources and sequenced load shedding will be made possible by proper incorporation of resources and loads. 


\section{BATTERY BASED ENERGY STORAGE OF POWER MANAGEMENT IN MICROGRID}

In the present situation, Battery based Energy Storage Elements play prominent role in Power management mainly in isolated microgrids. Different energy storage devices such as SMES,CESS were addressed in [31, 32]. In [33] wireless power management with battery. Load variation and uninterrupted supply will be managed with storage devices. Recently, many research works were being carried on the mode of communication in energy management, Konstantinos O. Oureilidis [33] highlighted new wireless mode of communication utilizing voltage magnitude and frequency to operate energy storage devices. With the combination of droop curves of two connected distributed energy resources, the operating frequency and voltage are set. The State of Charge in the battery will stop permitting to deep discharge and also charging and discharging were also depends on it, the desired limits will be a minimum of $20 \%$ and maximum will be $90 \%$ and thus ensures a longer life for battery. The control over the battery has been based on the measurement of frequency using PLL at the point of common coupling. An Analytical equation defined with maximum power load consumption and battery capacity, proposed to calculate the period of time microgrid feeding with battery.

\section{POWER MANAGEMENT WITH UTILIZATION OF HYBRID ENERGY STORAGE}

Junliu ZhangA [34], Etxeberria [35] and P. B. L. Neto [36] suggest the operation of the microgrid power management system executing in standalone mode. P.B.L.Neto [36] proposes a dual battery bank with the main bank having high capacity, able to store the energy to meet the load demand when renewable energy sources are connected or else secondary bank with low capacity to meet daily instantaneous load demand balance and voltage regulation. The main motive of the dual battery bank is to reduce the operational burden on the main battery bank. The main battery bank is costliest, we need to safeguard by taking the proper steps. In this paper, they have analyzed generation and demand curves to estimate the size of battery banks and by using charging and discharging time as a reference, clearly depicted the optimal sizing of main bank and small bank. The life of main bank is increased and the maintenance cost is reduced by more than $19 \%$. The Figure 2 shows the configuration of a domestic micro grid using hybrid storage system. Grid connected PV system has a Hybrid storage unit composed of Battery and Ultracapacitor. Inverter and a charger were used to manage PV system. The charger adjusts the charge and discharge of power of the battery and Ultracapacitor is directly connected to the inverter to minimize response time.

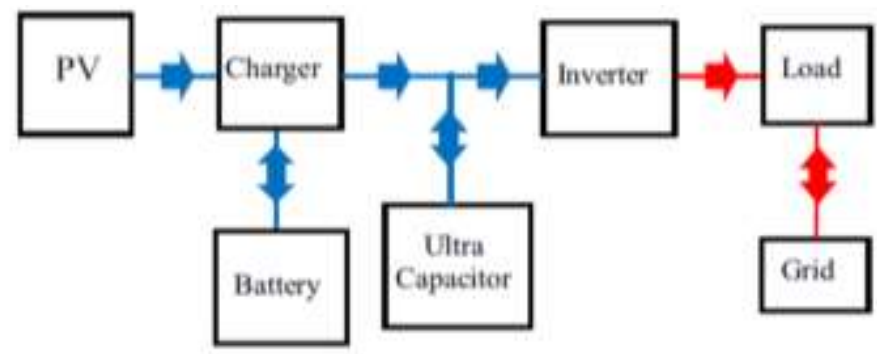

Figure 2. Configuration of a domestic microgrid using hybrid storage system

\section{MULTI AGENT BASED POWER MANAGEMENT}

The effective use of multi agent based Power management system discussed in [37-42]. The author H S V S Kumar Nunna [41] proposes a typical microgrid considering different agents for generation, load, energy market, auxiliary energy resource management and energy storage. Mainly concentrates on trading power in the energy market using agents, these agents shares information and calculates power imbalance and manages load demand with power supply. A case study of IEEE 37 bus radial system case study was also presented. Auxiliary energy management agents identify the optimal operating schedule of distributed energy storage systems and loads based on the received forecasted mismatch in power and prices. Ahmed M. Abdulmohsen [42], For islanded microgrids using Multi-Agent System (MAS) proposes a power management strategy. Cooperative agents act together to perform a task in MAS, it simplifies by dividing the system objective into several smaller objectives. The Proposed strategy reads forecasted data and performs Operational Power Flow and defines set points and sends to Field Agents. Field Agents were divided mainly to monitor and control bus load, dispatchable distributed generators, renewable generations 
and energy storage system. Based on detecting the island mode, Field Agents will receive initial intimation from Microgrid Central Agent (MGCA) and tries to operate at defined set points, the real time field measurements will be send back to MGCA. MGCA will update set points and sends back to field agents. Further, it will check for Islanded mode and repeats the mentioned process. Thus, the updated information plays a prominent role in calculating power mismatch between demand and generation.

\section{OPTIMIZATION TECHNIQUES BASED POWER MANAGEMENT}

The authors Xianjun Zhang [43], Martin Strelec [44], Daniel E.Olivares [45] and Luu Ngoc An [46] on optimization techniques proposes power management on the. Xianjun Zhang [43] worked on multi objective optimization for the microgrid to improve the system effectiveness and minimizing the ecological problems. Enhancing output power and decreasing operating cost is the main objective. The proposed model $[44,47]$ considers demand profiles received from a variety of resources such as grid, pv model, battery model, ICE model and thermal model. The data received in demand profiles has been given to multi objective functions for minimizing operating cost and maximizing the DG energy output. System constraints will pass the information to individual objective optimization and then sums up to form multi objective optimization.

Daniel E. Olivares [45], proposes a Centralized Energy Management System (CEMS) highly suitable for a standalone mode of operation of hybrid microgrid. In the model, the inputs to the CEMS are forecasting of non-dispatchable generation, electrical/thermal load, state-of-charge of energy storage system, operational limits, security and reliability constraints, main grid interconnection status and energy price forecasting. The outputs from CEMS are used as commands to controllable loads such as to On or Off or Shift, set points for dispatchable droop control and unit commitment. Thus, this paper dealt with existing EMS architectures and proposes a new CEMS architecture by consolidating the advantages in EMS architectures.

\section{CONCLUSION}

Over the past two decades, there is a wide area of technical developments in microgrid, this review provides detailed improvements and advancements of power management strategies in microgrid and enlightens the growth towards energy management principle. Discussed different approaches in the management of power such as the power electronic devices FACTS and storage devices, optimization techniques and multiagent based.

\section{REFERENCES}

[1] F. Katiraei, M. R. Iravani, and P.W. Lehn, "Micro-grid autonomous operation during and subsequent to islanding process," IEEE Trans. Power Del., vol. 20, no. 1, pp. 248-257, Jan. 2005.

[2] R. H. Lasseter and P. Paigi, "Microgrid: A conceptual solution", in Proc. 2004 IEEE Power Electron. Spec. Conf., Aachen, Germany, pp. 4285-4290, 2004.

[3] P. Piagi and R. H. Lasseter, "Autonomous control of microgrids," in Proc. 2006 IEEE Power Eng. Soc. Gen. Meeting, Montreal, QC, Canada, p. 8, 2006.

[4] L. A. de Souza Ribeiro, O. R. Saavedra, S. L. de Lima, and J. Gomes de Matos, "Isolated micro-grids with renewable hybrid generation: The case of Lençóis island,” IEEE Trans. Sustain. Energy, vol. 2, no. 1, pp. 1-11, Jan. 2011.

[5] X. Liu, P. Wang, and P. C. Loh, "A hybrid ac/dc microgrid and its coordination control," IEEE Trans. Smart Grid, vol. 2, no. 2, pp. 278-286, Jun. 2011.

[6] P. T. Baboli, M. Shahparasti, M. P. Moghaddam, M. R. Haghifam, and M. Mohamadian, "Energy management and operation modelling of hybrid ac-dc microgrid," IET Gener. Transm. Distri., vol. 8, no. 10, pp. 1700-1711, Oct. 2014

[7] Hristiyan Kanchev, Di Lu, Frederic Colas, Vladimir Lazarov, and Bruno Francois, "Energy Management and Operational Planning of a Microgrid With a PV-Based Active Generator for Smart Grid Applications", IEEE transactions on industrial electronics, vol. 58, no. 10, October 2011.

[8] Puladasuravi, B.Muralimohan, O.Hemakeshavulu, "Optimal placement of DSTATCOM for voltage sag mitigation using an anfis based approach for power quality enhancement", International Journal of Electrical, Electronics and Data Communication, vol. 2, Issue-1, Jan.-2014.

[9] E. Ozkop, A. M. Sharaf, I. H. Altas, “A Novel Control Algorithm for Self Adjusting Dynamic Voltage Stabilization Scheme”, Elektronika Ir Elektrotechnika, vol. 20, no. 3, 2014.

[10] Mehdi Savaghebi, Juan C.Vasquez, Alireza Jalilian, Joseph M.Guerrero, Tzung Lin Lee, "Selective compensation of voltage harmonics in grid-connected microgrids," Mathematics and Computers in simulation, vol 91, pp: 211-228, May 2013. 
[11] M. Gupta, S. Srivastava, J.R.P. Gupta, "Online Tracking and Mitigation of Voltage Flicker Using Neural Network," Journal of Control Engineering and Technology (JCET), vol. 2 no.1, pp.43-49, Jan 2012.

[12] Li YW, Vilathgamuwa DM, Loh PC, "Design, analysis and real-time testing of controllers for multibus microgrid system,” IEEE Trans Power Electronics, vol. 19, no. 5, pp. 1195-1204, Sept 2004.

[13] Hatziargyriou N, Asano H, Iravani R et al, “Microgrids," IEEE Power Energ Mag 5(4), pp:78-94, 2007.

[14] Rosemarie Velik, Pascal Nicolay, "Grid-price dependent energy management in microgrids using a modified simulated annealing triple-optimizer”, Applied Energy, no.130, pp: 384-395, 2014.

[15] Xuan Zhang, Jinjun Liu, and Ting Liu, "Virtual negatively resistive output impedance for power sharing among paralleled inverters in microgrid," 8th International Conference on Power Electronics, June 3, 2011.

[16] Roozbeh Morsali, Ryszard Kowalczyk, "Demand response based day-ahead scheduling and battery sizing in microgrid management in rural areas”, IET Renewable Power Generation, vol. 12, no. 14, pp:1651-1658, Oct 2018.

[17] F. Katiraei, and m. R. Iravani, "power management strategies for a microgrid with multiple distributed generation units," IEEE transactions on power systems, vol. 21, no. 4, pp: 1821-1831, Nov 2006.

[18] Dong Bo, Yongdong Li, and Zedong Zheng, "Energy Management of Hybrid DC and AC Bus Linked Microgrid," IEEE International Symposium on Power Electronics for Distributed Generation Systems, pp: 713-716, 2010.

[19] Hossam A. Gabbar, Abdelazeem A. Abdelsalam, "Microgrid energy management in grid-connected and islanding modes based on SVC," Energy Conversion and Management, no. 86, pp: 964-972, 2014.

[20] Ye Zhang, Hong JieJia, Li Guo, "Energy Management Strategy of Islanded Microgrid Based on Power Flow Control," IEEE PES, 2012.

[21] Chandorkar MC, Divan DM, Adapa R, "Control of parallel connected inverters in standalone AC supply systems," IEEE Trans on Industry Applications, vol.29, no.1, pp: 136-143, 1993.

[22] Guerrero JM, De Vicuñ a G, Matas J et al, "A wireless controller to enhance dynamic performance of parallel inverters in distributed generation systems," IEEE Trans Power Electronics, vol.19, no.5, pp:1205-1213, 2004.

[23] Poh Chiang Loh, Ding Li, Yi Kang Chai, and Frede Blaabjerg "Autonomous Operation of Hybrid Microgrid with AC and DC Sub-Grids," IEEE, 2011.

[24] Navid Eghtedarpour and Ebrahim Farjah, "Power Control and Management in a Hybrid AC/DC Microgrid," IEEE Trans on Smart Grid, vol 5, no.3, pp: 1494-1505, Apr 2014.

[25] Poh Chiang Loh, Ding Li,Yi Kang Chai and Frede Blaabjerg, "Autonomous Control of Interlinking Converter with Energy Storage in Hybrid AC-DC Microgrid," IEEE Trans on Industry Applications, vol 49, no.3, pp 1374-1382, 2013.

[26] Peng Wang, Chi Jin, Dexuan Zhu, Yi Tang ,Poh Chiang Loh and Fook Hoong Choo, "Distributed Control for Autonomous Operation of a Three-Port AC/DC/DS Hybrid Microgrid," IEEE Transactions On Industrial Electronics, vol 62,no.2, pp:1279-1290, Aug 2014.

[27] Yanghong Xia, Wei Wei, Miao Yu, Xiaoming Wang and Yonggang Peng "Power Management for a Hybrid AC/DC Microgrid With Multiple Subgrids,” IEEE Transactions On Power Electronics, vol. 33, no. 4, pp:3520-3533, April 2018.

[28] GrzegorzIwanski, PawelStaniak, WlodzimierzKoczara, "Power Management in a DC Microgrid Supported by Energy Storage, " IEEE International Symposium on Industrial Electronics, pp: 347-352, 2011.

[29] Luis E. Zubieta, "Power Management and Optimization Concept for DC Microgrids," International Conference on DC Microgrids, 2015.

[30] Mengchu Zhao, Qingguang Yu "Research of Voltage Control Strategy for Power Management System in DC Microgrid," IEEE ICEI, 2017.

[31] HaihuaZhou,Tanmoy Bhattacharya, Duong Tran, Tuck Sing Terence Siew and Ashwin M. Khambadkone, "Composite Energy Storage System Involving Battery and Ultracapacitor With Dynamic Energy Management in Microgrid Applications," IEEE transactions on power electronics, vol. 26, no. 3, March 2011.

[32] Seung-Tak Kim and Jung-Wook Park, "Energy Management Strategy and Adaptive Control for SMES in Power System with a Photovoltaic Farm," J Electrical Eng Technology, vol. 9, no. 4, pp: 1182-1187, 2014.

[33] Konstantinos O. Oureilidis, Charis S. Demoulias, "Microgrid Wireless Energy Management with Energy Storage System," IEEE International Conference, pp: 1-6, 2012.

[34] Junliu Zhang, DiankuiGuo, Fengping Wang YuechangZuo, Haiyan Zhang, "Research on Energy Management Strategy for Islanded Microgrid Based on Hybrid Storage Device,” IEEE International Conference on Renewable Energy Research and Applications, pp: 91-96, October 2013.

[35] A. Etxeberria, I. Vechiu, H. Camblong, J.-M. Vinassa, "Comparison of three topologies and controls of a hybrid energy storage system for Microgrids," Energy Conversion and Management, vol. 54, pp: 113-121, 2012.

[36] P. B. L. Neto, O. R. Saavedra and L. A. S. Ribeiro, "A Dual Battery Storage Bank Configuration For Isolated Microgrids Based On Renewable Sources," IEEE Transactions on Sustainable Energy, vol. 9, no.4, Oct 2018.

[37] Mao Meiqin, Dong Wei, Liuchen Chang, "Multi-Agent Based Simulation for Microgrid Energy Management," International Conference on Power Electronics, June 3, 2011.

[38] Frank Ibarra Hernández, Carlos Alberto Canesin, Ramon Zamora, Fransiska Martina, Anurag K, "Energy Management and Control for Islanded Microgrid Using Multi-Agents," North American Power Symposium, 2013.

[39] Cheol-HeeYoo, Il-Yop Chung, Hak-Ju Lee and Sung-Soo Hong, "Intelligent Control of Battery Energy Storage for Multi-Agent Based Microgrid Energy Management," Energies, vol.6, pp: 4956-4979, 2013.

[40] C.M. Colson and M.H. Nehrir "Algorithms for Distributed Decision-Making for Multi-agent Microgrid Power Management," IEEE Power and Energy Society General Meeting, 2011. 
[41] H S V S Kumar Nunna and Dipti Srinivasan, "A Multi-Agent System for Energy Management in Smart Microgrids with Distributed Energy Storage and Demand Response," International conference on Power Electronics, Drives and Energy Systems, 2016.

[42] Ahmed M. Abdulmohsen and Walid A. Omran, "Power Management in Islanded Microgrids Using Multi-Agent Systems," IEEE PES Innovative Smart Grid Technologies, 2016.

[43] Xianjun Zhan, Ratnesh Sharma and Yanyi He, "Optimal Energy Management of a Rural Microgrid System Using Multi-objective Optimization,” IEEE PES Innovative Smart Grid Technologies, 2012.

[44] Martin Strelec and Jan Berka, "Microgrid Energy Management based on Approximate Dynamic Programming," IEEE PES Innovative Smart Grid Technologies Europe (ISGT Europe), 2013.

[45] Daniel E. Olivares, Claudio A. Canizares and Mehrdad Kazerani, "A Centralized Energy Management System for Isolated Microgrids," IEEE Trans on Smart Grid, vol5, no.4, pp: 1864-1875, July 2014.

[46] Luu Ngoc An, Tran Thi Minh Dung and Tran Quoc-Tuan, "Optimal energy management for an on-grid microgrid by using Branch and Bound method," 2018 IEEE International Conference on Environment and Electrical Engineering and 2018 IEEE Industrial and Commercial Power Systems Europe (EEEIC / I\&CPS Europe), IEEE, 2018.

[47] Sattianadan. D, Kalyanasundaram. V, Vidyasagar.S, Roopam Jha, "Maximum power point tracking for a grid connected photovoltaic system using sliding mode control," International Journal of Power Electronics and Drive System. Vol. 8, no (4), pp. 1785-1792, December 2017. 